\title{
Dysfunctional uterine bleeding: ormeloxifene versus combined oral contraceptive pills
}

\author{
Sonia Luthra*, A. D. Dwivedi
}

Department of Obstetrics and Gynecology, Hind Institute of Medical Sciences, Safedabad, Barabanki, Uttar Pradesh, India

Received: 13 June 2018

Accepted: 07 July 2018

*Correspondence:

Dr. Sonia Luthra,

E-mail: drsonialuthra@gmail.com

Copyright: () the author(s), publisher and licensee Medip Academy. This is an open-access article distributed under the terms of the Creative Commons Attribution Non-Commercial License, which permits unrestricted non-commercial use, distribution, and reproduction in any medium, provided the original work is properly cited.

\section{ABSTRACT}

Background: Dysfunctional uterine bleeding is abnormal bleeding that occurs in the absence of recognizable pelvic pathology, general medical disease, or pregnancy. Globally, health care systems are focusing on low morbidity and low cost therapeutic interventions. Hence, medical treatment for DUB is high on the priority list. This comparative study was conducted to analyse the efficacy of ormeloxifene and combined oral contraceptive pills in reducing the blood loss and endometrial thickness in cases of DUB.

Methods: This prospective study was conducted on women with dysfunctional uterine bleeding, who attended Gynaecology OPD at Hind Institute of Medical Sciences, between August 2015 and April 2016. After applying inclusion and exclusion criteria, 72 women diagnosed with DUB were enrolled randomly in two groups A and B. Group A was treated by Ormeloxifene and Group B patients were treated with combined oral contraceptive pills for three consecutive cycles. The efficacies of the studied drugs were compared by analyzing the mean change in the pre and post treatment PBAC score, haemoglobin level and endometrial thickness using unpaired t-test.

Results: Ormeloxifene was found to be significantly more effective ( $\mathrm{p}<0.0001)$ than OCPs in controlling the menstrual blood loss (79\% reduction in group A Vs 55.5\% reduction in group B). Reduction in endometrial thickness was also more in the group receiving Ormrloxifene, however this was statistically not significant $(p=0.19)$. No major side effect observed with the use of Ormeloxifene.

Conclusions: Ormeloxifene can be an effective and safe therapy in the treatment of Dysfunctional uterine bleeding.

Keywords: Dysfunctional uterine bleeding, Oral contraceptive pills, Ormeloxifene, Selective estrogen receptor modulator

\section{INTRODUCTION}

Abnormal uterine bleeding is a significant health care problem for women, their families, and society as a whole. Up to $30 \%$ of women will seek medical assistance for this problem during their reproductive years. ${ }^{1}$ Because most cases are associated with anovulatory menstrual cycles, adolescents and perimenopausal women are particularly vulnerable., ${ }^{2,3}$ In today's world, where women represent a major sector of paid force in both the developing and developed countries, any regular source of debility like DUB has adverse economic, social and personal consequences.

Dysfunctional uterine bleeding is abnormal bleeding that occurs in the absence of recognizable pelvic pathology, general medical disease, or pregnancy. It reflects a disruption in the normal cyclic pattern of hormonal stimulation to the endometrial lining which is thought to be caused by dysfunction of hypothalamic-pituitaryovarian axis. ${ }^{4}$ DUB is a frequent indication for hysterectomy in developing countries. ${ }^{5}$ Globally, health 
care systems are focusing on low morbidity and low cost therapeutic interventions. Hence, medical treatment for DUB is high on the priority list.

Medical management of DUB is a challenging task. The options for initial management of DUB include antifibrinolytics, nonsteroidal anti-inflammatory drugs (NSAIDs), combined estrogen and progesterone pills, progesterones alone, high dose estrogens, gonadotropinreleasing hormone agonists, danazol and levonorgesterol releasing intrauterine systems. Cyclical combined oral contraceptive pills are widely used but side effects, especially in women over 40 years of age, have restricted their use. Danazol, progesterone and gonadotropinreleasing hormone analogues are all effective in terms of reducing menstrual blood loss, but adverse effects and costs limit their long-term use.

For the treatment of DUB authors need a drug, which blocks the action of estrogen on endometrium(antiestrogenic) but not its beneficial actions on other tissues. Selective estrogen receptor modulators (SERMs) have been identified to occupy a place in between estrogens and antiestrogens.

These compounds have estrogenic activities, which are tissue selective. Ormeloxifene is an optimally designed SERM, which behaves like an estrogen antagonist in uterus with mild estrogenic action on vagina, bone and serum lipids. ${ }^{6-8}$ Thus, it is especially beneficial in perimenopausal women as it has no uterine stimulation, prevents bone loss, does not increase the risk of breast cancer, lowers cholesterol level and maintains cognitive function of the brain. It has the additional advantage of reducing premenstrual symptoms, dysmenorrhoea and mastalgia. ${ }^{9}$

When ormeloxifene was used as a contraceptive, its beneficial effects on menorrhagia and endometriosis were observed, which led to controlled trials for the management of menorrhagia after approval was given by the Indian Drug Regulatory Authorities for this indication.

\section{METHODS}

A prospective study was conducted on women who were diagnosed as a case of dysfunctional uterine bleeding at out-patient department of Obstetrics and Gynaecology at Hind Institute of Medical Sciences, Safedabad, Barabanki between August 2015 and April 2016.

Out of total of 345 cases of abnormal uterine bleeding, 115 were found to have DUB. Total 72 patients were selected according to exclusion and inclusion criteria. Written informed consent for drug trial was taken.

\section{Inclusion criteria}

- Women between menarche and menopause
- $\quad$ AUB cases having no evidence of pelvic pathology on clinical examination or USG.

\section{Exclusion criteria}

- Pregnancy related bleeding like abortion or ectopic pregnancy

- Hypersensitivity to the drug

- Any hormonal therapy including oral contraceptive pill usage within last 3 months

- Any IUCD used or removed within last 6 months.

- Positive cervical cytology and colposcopic examination or suspicious cervix

- History of breast malignancy or any palpable lump in breasts

- Current genital infection

- Active bleeding necessitating emergency treatment

- Patient with severe anaemia ( $\mathrm{Hb}<6$ gm \%)

- Any systemic diseases such as liver disorders, platelet disorder or coagulopathy

- Previous history of thrombosis or of migraine.

Selected patients of dysfunctional uterine bleeding who consented for drug trial study and for regular follow up, were included in the study and were divided into following two groups:

\section{Group A (Ormeloxifene group):}

It was comprised of 36 patients who were prescribed Ormeloxifene $60 \mathrm{mg}$ twice a week for twelve weeks.

\section{Group B (Combined oral contraceptive group):}

This group was comprised of 36 patients who were prescribed combined oral contraceptive pills (containing ethinyl estradiol $30 \mu \mathrm{g}$ and levonorgestrel $0.3 \mathrm{mg}$ ) for twenty-one days starting from third day of menses followed by seven pill free days. This treatment was continued for three consecutive cycles.

All women were instructed to use sanitary napkin of similar kind, not containing absorbent gel. A detailed menstrual history and physical examination was done at each visit at monthly interval. Any side effects observed were noted. The subjective improvement of symptoms and acceptability of drugs were enquired. The efficacy of drugs, subjective and objective findings of improvement in the condition of patient, tolerance to the drug and side effects were noted.

The main outcome to be measured were menstrual blood loss by PBAC score, blood hemoglobin levels in $\mathrm{gm} / \mathrm{dl}$ and endometrial thickness in $\mathrm{mm}$, on 18-21 day of menstrual cycle by trans-vaginal sonography (TVS).

Pictorial Blood loss Assessment Chart (PBAC) (Higham et al., 1990) 10 was used to measure the menstrual blood loss (MBL). Scores were assigned to different degrees of 
soiling of sanitary napkins and number and size of clots passed at every cycle as per Figure 1.

\begin{tabular}{|l|l|l|}
\hline \multicolumn{3}{|c|}{ Pads } \\
\hline $\mathbf{1}$ point & For each lightly stained pad \\
\hline $\mathbf{5}$ points & For each moderately stained pad \\
\hline $\mathbf{2 0}$ points & For each completely saturated pad \\
\hline $\mathbf{1}$ point & For each lightly stained tampon \\
\hline $\mathbf{5}$ points & For each moderately stained tampon \\
\hline $\mathbf{1 0}$ points & For each completely saturated tampon \\
\hline $\mathbf{1 p o i n t}$ & For each small clot (size of a rupee coin/smaller) \\
\hline $\mathbf{5}$ point & For each larger clot (larger than a rupee coin) \\
\hline
\end{tabular}

Figure 1: Blood loss assessment chart.

\section{Statistical analysis}

PBAC score, haemoglobin concentration and endometrial thickness were measured before the start of therapy and at end of 3 months i.e. after the completion of therapy. Statistical parameters were used as Mean \pm Standard Deviation and data were analysed using the paired $t$ test. The change in mean PBAC and endometrial thickness in two groups were compared using unpaired t-test. Statistical significance was taken at $\mathrm{p}$ value $\leq 0.05$.

\section{RESULTS}

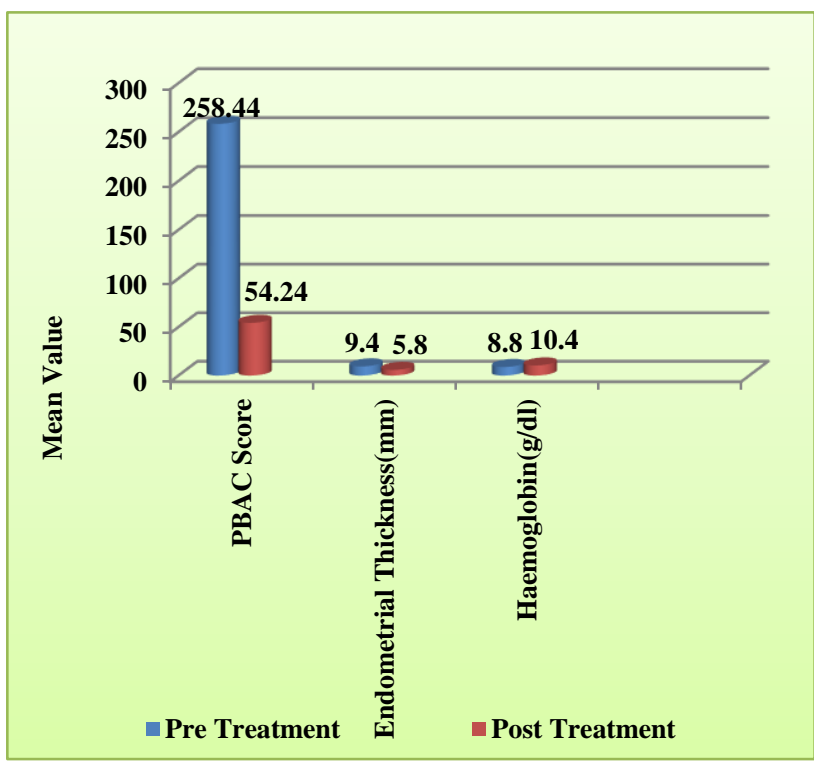

Figure 2: Group A (Ormeloxifene) Comparison between pre-treatment and post treatment Values.

Out of these 72 patients of DUB 17 were lost to follow up and hence were excluded from the study. In Ormeloxifene group (group $\mathrm{A}, \mathrm{N}=27$ ), patients showed a significant reduction in mean PBAC score from 258.44 to 54.24 i.e. $79 \%$ reduction in menstrual blood loss. Similarly, a significant reduction in endometrial thickness was seen after treatment $(\mathrm{P}$ value $<0.0001)$. A significant improvement in anemia was also seen inspite of no iron therapy given along with Ormiloxifene therapy (Figure 2).

In Combined oral contraceptive group (group $\mathrm{B}, \mathrm{N}=28$ ), $\mathrm{p}$ value $<0.0001$ indicates significant reduction in mean PBAC score from 221.34 to 98.45 (55.5\%) after treatment. A significant reduction in endometrial thickness $(\mathrm{P}<0.0001)$ was also seen. A significant rise in haemoglobin level was observed $(\mathrm{P}<0.0001)$ after three months treatment with combined oral contraceptive pills, with no iron supplementation (Figure 3). On comparing group, A and group B, ormeloxifene was found significantly better than combined OCP in reduction of menstrual blood loss (79\% vs $55.52 \%$ reduction with $\mathrm{p}$ value $<0.0001)$ in cases of DUB. Reduction in mean endometrial thickness was also better in Ormeloxifene group than in combined OCPs group, but statistically it was not found significant ( $p$ value- 0.19 ).

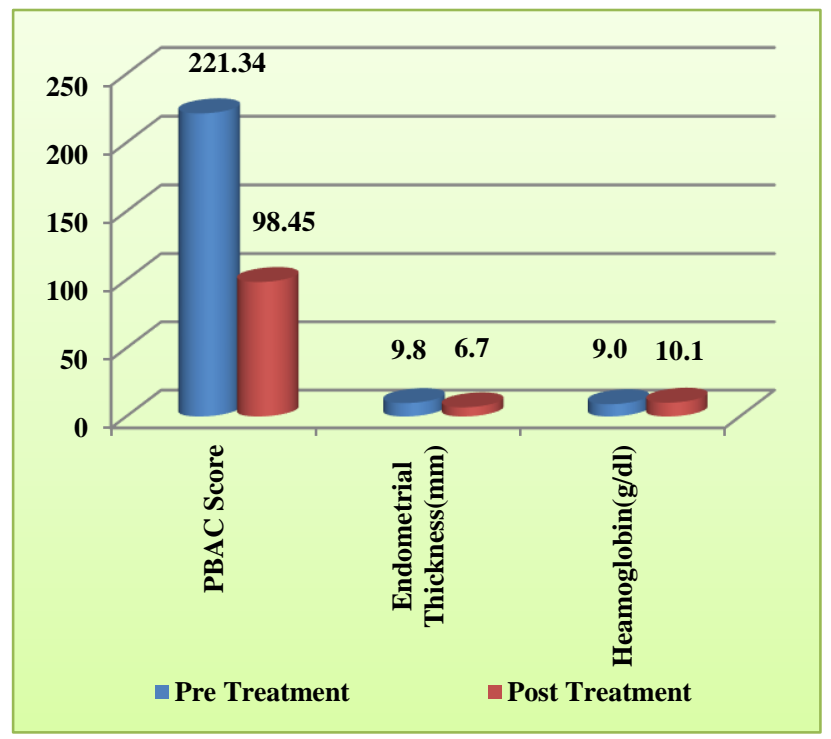

Figure 3: Pre-treatment and post-treatment values in Group B (Combined OCPs).

There was no major side effect with Ormeloxifene. Amenorrhea was the main symptom seen in 5 cases $(18.5 \%)$. Nausea, vomiting, ovarian cysts and headache were other side effects, but neither was significant enough to stop the therapy. In patients receiving combined oral contraceptive pills main symptom was gastric upset (in $32 \%$ of cases). Breast tenderness and weight gain were other symptoms.

\section{DISCUSSION}

The problem of dysfunctional uterine bleeding i.e. excessive or prolonged regular or irregular menstrual bleeding in the absence of overt uterine pathology, 
endocrine or haematological disorder is a common reason for consultation in gynaecological out-patient departments. In recent years basic physiological research has resulted into a greater depth of insight into the mechanisms involved in the control of normal menstruation and the pathophysiology of dysfunctional uterine bleeding (DUB).

DUB can occur at any time between puberty to menopause and may be either ovulatory or anovulatory. A history of excessive bleeding with regular menstrual cycles is usually associated with ovulation. An anovulatory pattern of bleeding with erratic intervals between menstrual periods can also occur. Typically, the anovulatory pattern occurs at puberty prior to the onset of regular menstruation and also in women in their mid-30s onwards. It may also be seen in women with PCOD where there is peripheral conversion of androgens to estrogens. Ovulatory bleeding patterns are more common than anovulatory.

Newer drug therapies and the development of less invasive surgical techniques are in need of further clinical trials. The approach to management is to ensure general well-being and improve quality of life in addition to control the bleeding. Medical management and avoidance of surgery is always recommended, as the short period of drug therapy bridges the temporary phase of menstrual alterations successfully, wherein young subjects settle down with normal cycles and elderly subjects attain menopause. Ormeloxifene can be a good option with its properties of creating a hypoestrogenic environment without disturbing other estrogenic positive effects. Side effects like weight gain or breast tenderness, depression, mood changes, mastalgia and poor libido are not there with Ormeloxifene. It is also devoid of androgenic ill effects such as acne and hirsutism. Being a metabolically non-controversial agent, complications such as hypertension, coagulation disorders, hyperglycemia and abnormal lipid profile, which are common with combined OCP, do not occur.

Ormeloxifene also offers perimenopausal bone and cardiovascular protection. It is found oncologically protective to the breast and the endometrium.

In present study authors have analyzed the efficacy of Ormeloxifene in patients with dysfunctional uterine bleeding and our results suggested that there was a significant reduction ( $p$ value $<0.0001$ ) in menstrual blood loss (mean PBAC score reduction of $79 \%$ from 258.44 to 54.24 ) after three months of treatment. These results are consistent with the study conducted at AIIMS by Kriplani A. et al, which showed reduction in median PBAC score from 388 (range 169-835) to 80 (range 0730 ) and 5 (range 0-310) at 2 and 4 months respectively (p value <0.001). ${ }^{11}$ The reduction in PBAC score was $97.7 \%$ at 4 months. Shravage et al, 2011 concluded that there was a significant reduction in the menstrual blood loss of $85 \%$ in patients treated with Ormeloxifene. ${ }^{12}$
The results of the present study showed that there was a significant rise of haemoglobin of $1.6 \mathrm{gm} / \mathrm{dl}(\mathrm{p}<0.0001)$ after three months treatment with Ormeloxifene. It is consistent with other studies. Dhananjay BS et al, 2012 showed that there was a statistically significant increase in the haemoglobin level $(\mathrm{p}<0.001)$ after the treatment with ormeloxifene. ${ }^{13}$ Agarwal, et al also concluded that mean pretreatment $\mathrm{Hb}$ concentration significantly increased from $9.04 \mathrm{gm} \%$ to $10.01 \mathrm{gm} \%$ at 3 months and to $10.86 \mathrm{gm} \%$ at 6 months ( $\mathrm{p}<0.0001$ ) in patients of DUB treated with Ormeloxifene. ${ }^{14}$

Shravage et al, found that the mean pre-treatment endometrial thickness was reduced from $7.81 \mathrm{~mm}$ to 4.94 mm after 3 months of therapy. ${ }^{12}$ Dhananjay BS et al, 2012 showed that there was a statistically significant reduction in the endometrial thickness $(\mathrm{p}<0.001)$ after the treatment with ormeloxifene. ${ }^{13}$

In present study mean pre-treatment endometrial thickness reduced from $9.4 \mathrm{~mm}$ to $5.8 \mathrm{~mm}$ after treatment, showing a significant reduction $(\mathrm{p}<0.0001)$. A total of about $81 \%$ of patients responded well with Ormeloxifene. The results were corresponding to the results of above mentioned studies.

\section{CONCLUSION}

From above observations, it can be concluded that the ormeloxifene is more effective than combined oral contraceptive therapy in controlling the menstrual blood loss in cases of DUB. Apart from its efficacy, Ormeloxifene has shown its superiority by good compliance and less stringent eligibility criterion. Thus, it may be considered for the medical management of idiopathic menorrhagia, especially in peri-menopausal women, in adolescents and in women who wish to preserve their fertility.

Funding: No funding sources

Conflict of interest: None declared

Ethical approval: The study was approved by the Institutional Ethics Committee

\section{REFERENCES}

1. Singh S, Best C, Dunn S, Leyland N, Wolfman WL, Wolfman W, et al. Abnormal uterine bleeding in premenopausal women. J Obstet Gynaecol Canada. 2013;35(5):473-5.

2. Bennett AR, Gray SH. What to do when she's bleeding through: the recognition, evaluation, and management of abnormal uterine bleeding in adolescents. Current Opin Pediat. 2014;26(4):413-9.

3. Rezk M, Masood A, Dawood R. Perimenopausal bleeding: Patterns, pathology, response to progestins and clinical outcome. J Obstet Gynaecol. 2015;35(5):517-21.

4. Khrouf M, Terras K. Diagnosis and management of formerly called "dysfunctional uterine bleeding" 
according to PALM-COEIN FIGO classification and the new guidelines. J Obst Gynecol India. 2014;64(6):388-93.

5. Abid M, Hashmi AA, Malik B, Haroon S, Faridi N, Edhi MM, et al. Clinical pattern and spectrum of endometrial pathologies in patients with abnormal uterine bleeding in Pakistan: need to adopt a more conservative approach to treatment. BMC Women's Health. 2014;14(1):132.

6. Biswas SC, Saha SK, Bag TS, Ghosh Roy SC, Roy AC, Kabiraj SP. Ormeloxifene: A selective estrogen receptor modulator for treatment of dysfunctional menorrhagia. J Obstet Gynecol Ind. 2004;54(1):5659.

7. ACOG practice bulletin selective oestrogen receptor modulators. Clinical management guidelines for Obstetricians Gynecologists 2002;39(4):835-44.

8. Shelly W, Draper MW, Krishnan V, Wong M, Foffe RB. The selective oestrogen receptor modulators: An update on recent clinical findings. Obstet Gynecol Survey. 2008;63(3):163-81.

9. Tejwani PL, Srivastava A, Nerkar H, Dhar A, Hari S, Thulkar S, et al. Centchroman regresses mastalgia: a randomized comparison with danazol. Indian J Surg. 2011;73(3):199-205.
10. Higham JM, O'brien PM, Shaw R. Assessment of menstrual blood loss using a pictorial chart. BJOG: Int J Obstet Gynaecol. 1990;97(8):734-9.

11. Kriplani A, Kulshrestha V, Agarwal N. Efficacy and safety of ormeloxifene in management of menorrhagia: a pilot study. J Obstet Gynaecol Res. 2009;35(4):746-52.

12. Shravage J, Mekhala D, Bellad MB, Ganachari MS, Dhumale HA. Ormeloxifene versus Medroxyprogesterone Acetate (MPA) in the treatment of Dysfunctional Uterine Bleeding: A double-blind randomized controlled trial. J South Asian Fed Obstet Gynecol. 2011;3(1):21-4.

13. Dhananjay BS, Nanda SK. The role of sevista in the management of dysfunctional uterine bleeding. J Clin Diag Res: JCDR. 2013;7(1):132.

14. Agarwal N, Singh S. The efficacy and safety of ormeloxifene in dysfunctional uterine bleeding. Age (years). 2013;32:20-50.

Cite this article as: Luthra S, Dwivedi AD. Dysfunctional uterine bleeding: ormeloxifene versus combined oral contraceptive pills. Int J Reprod Contracept Obstet Gynecol 2018;7:3610-4. 